\title{
Topical timolol for a chronic ulcer - a case with its own control
}

\begin{abstract}
A trial of topical timolol solution in a 92-year-old patient with two chronic leg ulcers resulted in rapid healing of the treated ulcer. While this finding needs to be confirmed, topical timolol is a simple, inexpensive therapy that has the potential to help heal refractory wounds.
\end{abstract}

\begin{abstract}
Melissa N Manahan BPharm, MB BS(Hons), Dermatology Registrar

Peter Peters BSc(Hons), MB BS, Dermatology Registrar,' and Associate Lecturer ${ }^{2}$

Salvatore Scuderi $\mathrm{BSc}$, BMedSci, MB BS(Hons) Dermatology Registrar

Devita Surjana BSC, MB BS, Dermatology Registrar

Graeme L Beardmore OAM, MB BS, DDM, FACD, Dermatologist

1 Queensland Institute of Dermatology, Brisbane, QLD.

2 School of Medicine University of Queensland,
Brisbane, QLD.

melissa.manahan@ uqconnect.edu.au
\end{abstract}

doi: 10.5694/mjal3.10823

\section{Clinical record}

In October 2012, a 92-year-old woman was referred to the Queensland Institute of Dermatology by a plastic surgeon for the ongoing management of two chronic ulcers on her left leg, attributed to peripheral vascular disease. Significant other medical history included ischaemic heart disease, chronic back pain, a prior cerebrovascular accident, hypertension, previous deep vein thrombosis and episodes of cellulitis in her left leg. The medications that she was taking included aspirin, enoxaparin, nicorandil, spironolactone, amiodarone, rabeprazole, frusemide, digoxin, perindopril, hydrochlorothiazide and bisoprolol.

Management of the ulcers included treating the concomitant infection with oral antibiotics and twice weekly dressing changes with alginate and foam dressings. Ultrasonic wound debridement was performed twice weekly from November 2012. The aim of this procedure was to remove slough in the base of each wound via conversion of ultrasonic energy to mechanical vibration through a saline irrigation fluid. However, after 4 months of this treatment there was no improvement. At this time, the patient was admitted to hospital for a general decline in health, awaiting nursing home placement.

By March 2013, the ulcers had been present for about 18 months. Based on reports of a case of successful use of topical timolol for a chronic, traumatic ulcer, ${ }^{1,2}$ we discussed the possibility of using this off-label treatment with our patient. Reports of the previous case indicated that the timolol treatment had not caused any significant adverse effects, and we were able to monitor our patient closely on initiation of timolol treatment as she was an inpatient. She consented to the treatment and we commenced application of four drops of $0.5 \%$ timolol maleate ophthalmic solution once a day to the medial ulcer, while the lateral ulcer served as a control. Both were occluded with a hydrocolloid fibre and silicone foam dressing. At baseline, the medial ulcer measured $5.0 \times 4.0 \mathrm{~cm}$ and the lateral ulcer measured $4.8 \times 4.5 \mathrm{~cm}$ (Box 1 , Box 2). At the 6 -week review, the medial ulcer had reduced in size to $4.0 \times 2.2 \mathrm{~cm}$ and ward staff requested that the lateral ulcer also be treated with timolol as it had deteriorated. At 12-week review, the medial ulcer's wound base had completely re-epithelialised and timolol treatment was ceased for this ulcer. The lateral ulcer reduced in size after 6 weeks of timolol treatment, although there had been a small increase in size after 1 week of timolol treatment. No local irritation or other adverse effects from the treatment were seen.

\section{Discussion}

Chronic ulcers are a common problem, particularly in older people. The reported prevalence of chronic wounds in people in the United Kingdom (in community and hospital settings) ranges from 3.55 to 3.73 per 1000 population. ${ }^{3,4}$ Chronic leg ulcers have a reported point prevalence of $0.11 \%$ in an Australian community. ${ }^{5}$ Based on UK surveys, wound care is estimated to cost between $1.44 \%$ and $3 \%$ of the local health care budget, which includes the cost of hospital admissions, nursing care and dressings. 3,4

$\beta$-Receptor antagonists are inexpensive therapies which have shown promise in wound healing. $\beta 2$-Adrenoceptors are located on keratinocytes. While $\beta$-Receptor antagonism can improve keratinocyte migration, particularly to the wound centre, ${ }^{6} \beta$-Agonists have the opposite effect via a phosphatase $2 \mathrm{~A}$-dependent mechanism. ${ }^{7} \quad \beta$-Blockade also appears to enhance angiogenesis in the wound. ${ }^{8}$ When mice are chronically stressed, they have higher levels of catecholamines, which impair wound healing, and high doses of oral propranolol have been shown to block this effect. ${ }^{9} \beta$-blockers are also useful in the treatment of infantile haemangiomas, with theorised mechanisms including vasoconstriction and antiangiogenesis. ${ }^{10}$ This mechanism appears to be in contrast to the effect $\beta$ Blockers have on wound healing in promoting angiogenesis, and the reason for the apparent contradiction is unclear. The potential dual benefit is being considered in a clinical trial for the treatment of ulcerated haemangiomas (Timolol Option for Ulcerated Hemangiomas [TOUCH] trial), using the gel-forming solution vehicle. ${ }^{11}$

Timolol has the potential to be an inexpensive, noninvasive and non-labour intensive means to assist wound healing for chronic ulcers. A Phase II trial, looking at the use of topical timolol in ulcers, was halted due to lack of funding. ${ }^{12}$ It is not clear whether systemic absorption of timolol occurs when it is used topically for wounds, as most of the data on systemic absorption are based on its ophthalmic use. ${ }^{13}$ Serum level measurements are planned 


\section{Case reports}

1 Intervention: medial ulcer at baseline and 6-week, 7-week and 12-week reviews (timolol given from baseline)
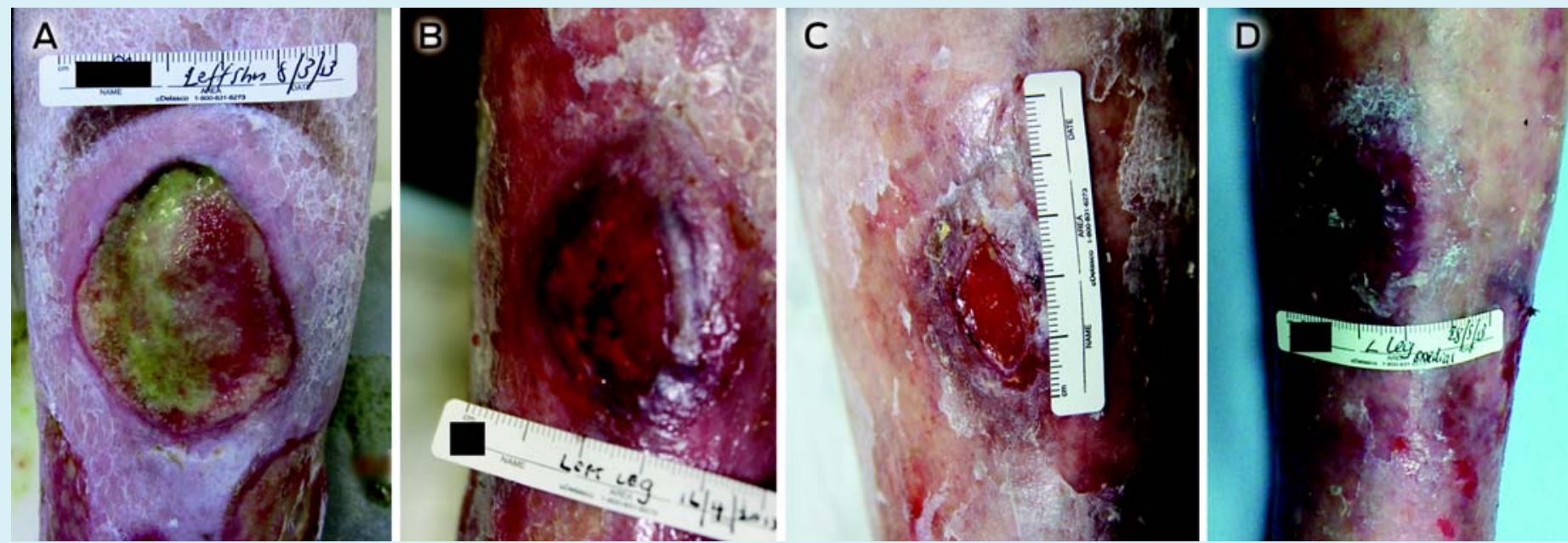

At baseline, the ulcer measured $5.0 \times 4.0 \mathrm{~cm}(\boldsymbol{A})$. Topical timolol treatment was then commenced. At the 6 -week review ( 6 weeks of timolol), the ulcer measured $4.0 \times 2.2 \mathrm{~cm}(\boldsymbol{B})$; at the 7 -week review ( 7 weeks of timolol), it measured $2.0 \times 1.5 \mathrm{~cm}(\boldsymbol{C})$; and at the 12 -week review (12 weeks of timolol), the wound base had competely re-epithelialised (D).

\section{Control: lateral ulcer at baseline and 6-week, 7-week and 12-week reviews (timolol given from 6 weeks)}
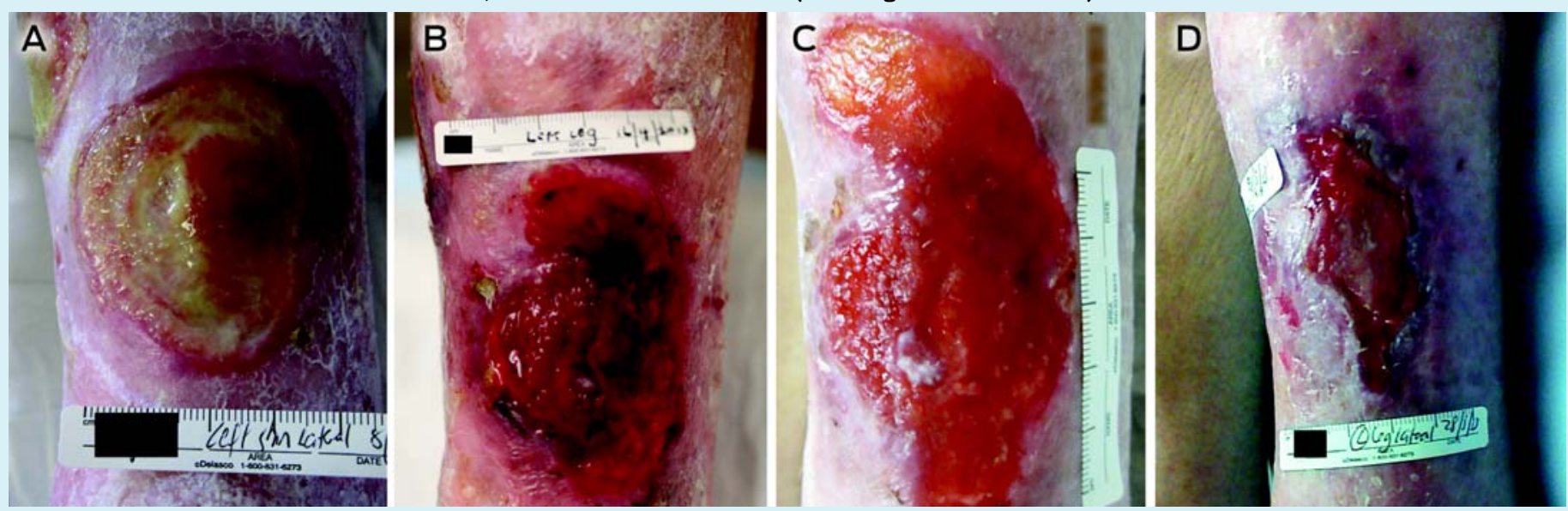

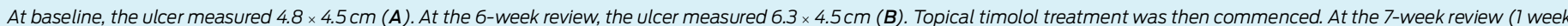
of timolol), the ulcer measured $7.0 \times 5.0 \mathrm{~cm}(\mathrm{C})$. At the 12 -week review ( 6 weeks of timolol), the ulcer measured $5.0 \times 2.0 \mathrm{~cm}(D)$.

in the TOUCH trial ${ }^{11}$ and it is important to consider the possibility of systemic absorption in clinical practice. Further investigations into this therapy are required to determine the utility of topical timolol in mainstream care, such as its possible value in reducing healing time for surgical ulcers with failed grafts. To our knowledge, this is the first report on using topical timolol to treat a chronic ulcer secondary to peripheral arterial disease.

Competing interests: No relevant disclosures.

Received 19 Jun 2013, accepted 23 Sep 2013.

1 Tang J, Dosal J, Kirsner R. Topical timolol for a refractory wound. J Am Acad Dermatol 2012; 66 (4 Suppl 1): AB12.

2 Tang JC, Dosal J, Kirsner RS. Topical timolol for a refractory wound. Dermatol Surg 2012; 38: 135-138.

3 Drew P, Posnett J, Rusling L. The cost of wound care for a local population in England. Int Wound J 2007; 4: 149-155.

4 Vowden K, Vowden P, Posnett J. The resource costs of wound care in Bradford and Airedale primary care trust in the UK. J Wound Care 2009; 18: 93-94, 96-98, 100 passim
5 Baker SR, Stacey MC. Epidemiology of chronic leg ulcers in Australia. Aust NZ J Surg 1994; 64: 258-261.

6 Pullar CE, Rizzo A, Isseroff RR. Beta-adrenergic receptor antagonists accelerate skin wound healing: evidence for a catecholamine synthesis network in the epidermis. J Biol Chem 2006; 281: 21225-21235.

7 Pullar CE, Grahn JC, Liu W, Isseroff RR. Beta2-adrenergic receptor activation delays wound healing. FASEB J 2006; 20:76-86.

8 Pullar CE, Le ProvostGS, O'Leary AP, et al. $\beta 2 A R$ antagonists and $\beta 2$ AR gene deletion both promote skin wound repair processes. J Invest Dermatol 2012; 132: 2076-2084.

9 Romana-Souza B, Porto LC, Monte-Alto-Costa A. Cutaneous wound healing of chronically stressed mice is improved through catecholamines blockade. Exp Dermatol 2010; 19: 821-829.

10 Léauté-Labrèze C, Dumas de la Roque E, Hubiche T, et al. Propranolol for severe hemangiomas of infancy. New Engl J Med 2008; 358: 2649-2651.

11 Children's Hospital of Philadelphia. Timolol Option for Ulcerated Hemangiomas (TOUCH Trial). Clinical Trials.gov identifier NCT01408056. http:// clinicaltrials.gov/show/NCT01408056 (accessed Jul 2013).

12 University of California, Davis. Beta Blocker for Chronic Wound Healing. ClinicalTrials.gov identifier NCT00368602. http://clinicaltrials.gov/ct2/show/ study/NCT00368602?view=results (accessed Jun 2013).

13 McMahon P, Oza V, Frieden IJ. Topical timolol for infantile hemangiomas: putting a note of caution in "cautiously optimistic". Pediatr Dermatol 2012; 29: 127-130. 